
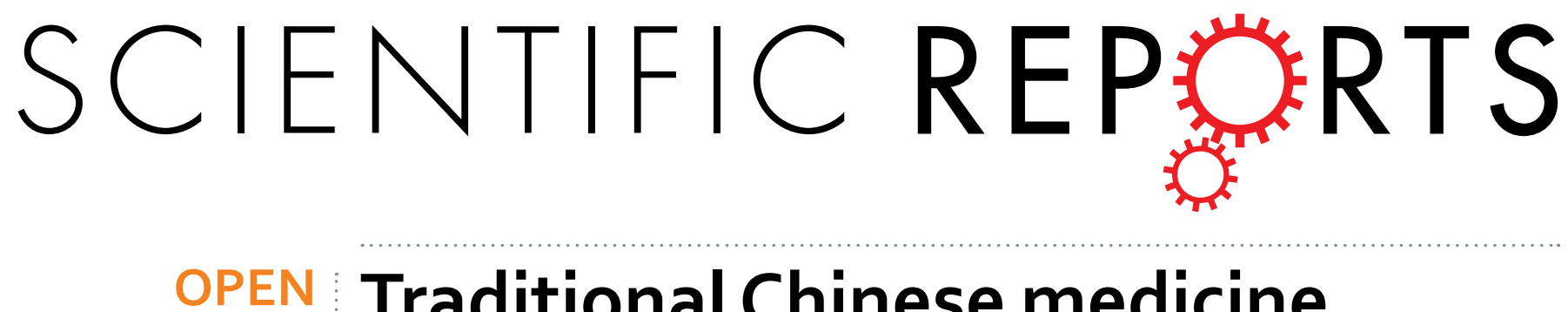

\title{
Traditional Chinese medicine
} suppresses left ventricular hypertrophy by targeting

Received: 10 October 2016 Accepted: 17 January 2017 Published: 22 February 2017 extracellular signal-regulated
kinases signaling pathway in
spontaneously hypertensive rats

Xingjiang Xiong ${ }^{1}$, Xiaochen Yang ${ }^{1}$, Lian Duan ${ }^{1}$, Wei Liu ${ }^{2}$, Yun Zhang ${ }^{3}$, Yongmei Liu ${ }^{3}$, Pengqian Wang ${ }^{4}$, Shengjie $\mathrm{Li}^{5}$ \& Xiaoke $\mathrm{Li}^{6}$

Chinese herbal medicine Bu-Shen-Jiang-Ya decoction (BSJYD) is reported to be beneficial for hypertension. Over expression of extracellular signal regulated kinases (ERK) pathway plays an important role in left ventricular hypertrophy (LVH). This study aimed to observe effects of BSJYD on LVH in spontaneously hypertensive rats (SHRs) and explore its possible mechanism on regulation of ERK pathway. Sixty 12-week-old SHRs were randomly allocated into 5 groups: BSJYD high dose group, middle dose group, low dose group, captopril group, and control group. Besides, a control group of Wistar-Kyoto rats was established. All rats were treated for 8 weeks. Systolic blood pressure (SBP), heart rate (HR), pathology, and left ventricular mass index (LVMI) were measured. Western blotting and Real-time PCR were used to assess the expressions of BDNF, Ras, ERK1/2, and c-fox levels. SBP and HR were significantly decreased compared with the control group and LVMI was markedly improved by BSJYD treatment in a dose-dependent manner. BSJYD inhibited the expression of BDNF, Ras, ERK1/2, and c-fox mRNA in LVH. In conclusion, BSJYD suppressed hypertension-induced cardiac hypertrophy by inhibiting the expression of ERK pathway. These changes in gene expression may be a possible mechanism by which BSJYD provides myocardial protection from hypertension.

Hypertension is an important worldwide public health challenge because of its high prevalence and concomitant increase in risks of cardiovascular, cerebrovascular and renal diseases ${ }^{1,2}$. It has been identified as the leading risk factor for mortality in human populations, and is ranked third as a cause of disability-adjusted life-years ${ }^{3,4}$. Hypertension is not only manifested by an elevated arterial blood pressure (BP), but also involves complex structural and functional alterations of its target organs $s^{5}$. In the hypertensive state, a number of adaptive changes occur in ventricle. Cardiac hypertrophy results from increased mechanical load on the heart and through the action of neurohumoral mediators. Left ventricular hypertrophy $(\mathrm{LVH})$ is a cardinal manifestation of hypertensive organ damage associated with an increased cardiovascular morbidity and mortality ${ }^{6,7}$. LVH in hypertensive patients may be regarded as a powerful, independent biomarker reflecting the impact of pressure overload as well as of several risk factors on heart ${ }^{8}$. These structural abnormalities may play an important role in the development and

${ }^{1}$ Department of Cardiology, Guang'anmen Hospital, China Academy of Chinese Medical Sciences, Beijing, China. ${ }^{2}$ Department of Cardiology, Beijing Hospital of Traditional Chinese Medicine, Capital Medical University, Beijing, China. ${ }^{3}$ Department of Molecular Biology, Guang'anmen Hospital, China Academy of Chinese Medical Sciences, Beijing, China. ${ }^{4}$ Department of Pharmacology, Institute of Chinese Materia Medica, China Academy of Chinese Medical Sciences, Beijing, China. ${ }^{5}$ Department of Molecular Biology, Peking Union Medical College Hospital, Chinese Academy of Medical Sciences, Beijing, China. ${ }^{6}$ Bio-organic and Natural Products Laboratory, McLean Hospital, Harvard Medical School, Belmont, USA. Correspondence and requests for materials should be addressed to X.X. (email: 5administration@163.com) 


\begin{tabular}{|l|c|c|c|c|}
\hline Group & n & 0 week & 4 weeks & 8 weeks \\
\hline WKY & 12 & $120.71 \pm 8.79^{* *} \mathbf{\Lambda}$ & $125.98 \pm 9.08^{* *} \mathbf{\Lambda}$ & $126.77 \pm 8.54^{* *}$ \\
\hline C & 12 & $201.73 \pm 9.43$ & $212.63 \pm 8.16^{\mathbf{\Lambda}}$ & $218.65 \pm 9.72^{\mathbf{\Lambda}}$ \\
\hline Ca & 12 & $200.66 \pm 10.56$ & $164.77 \pm 8.52^{* *}$ & $170.28 \pm 10.12^{* *}$ \\
\hline Bh & 12 & $202.27 \pm 9.06$ & $184.37 \pm 10.35^{* *} \mathbf{\Lambda}$ & $178.13 \pm 8.76^{* *}$ \\
\hline Bm & 12 & $201.54 \pm 10.06$ & $193.03 \pm 9.89^{\mathbf{\Lambda}}$ & $188.04 \pm 7.86^{* \boldsymbol{\Lambda}}$ \\
\hline $\mathrm{Bl}$ & 12 & $200.81 \pm 9.32$ & $190.17 \pm 8.91 \mathbf{\Lambda}$ & $190.65 \pm 9.79^{* * \mathbf{\Lambda}}$ \\
\hline
\end{tabular}

Table 1. Effect of Bu-Shen-Jiang-Ya decoction on systolic blood pressure. ${ }^{\star} \mathrm{P}<0.05,{ }^{*} P<0.01$, significantly different from the C group. $\boldsymbol{\Delta}_{P}<0.05, \mathbf{\Delta} \mathbf{\Delta} P<0.01$, significantly different from the Ca group.

\begin{tabular}{|c|c|c|c|c|}
\hline Group & $\mathbf{n}$ & 0 week & 4 weeks & 8 weeks \\
\hline WKY & 12 & $366.74 \pm 26.83^{* *} \boldsymbol{\Delta} \boldsymbol{\Delta}$ & $345.91 \pm 25.42^{* *} \boldsymbol{\Delta} \boldsymbol{\Delta}$ & $331.77 \pm 27.92^{* *}$ \\
\hline $\mathrm{C}$ & 12 & $412.89 \pm 19.56$ & $396.26 \pm 23.83 \mathbf{\Delta} \boldsymbol{\Delta}$ & $370.51 \pm 23.91 \boldsymbol{\Delta} \boldsymbol{\Delta}$ \\
\hline $\mathrm{Ca}$ & 12 & $408.36 \pm 20.72$ & $391.88 \pm 22.61$ & $361.69 \pm 20.07$ \\
\hline $\mathrm{Bh}$ & 12 & $402.52 \pm 24.07$ & $376.63 \pm 23.01^{* \boldsymbol{\Delta}}$ & $344.43 \pm 18.93^{* *} \boldsymbol{\Delta}$ \\
\hline $\mathrm{Bm}$ & 12 & $399.25 \pm 25.80$ & $394.42 \pm 22.80$ & $383.74 \pm 27.03^{\Delta}$ \\
\hline $\mathrm{Bl}$ & 12 & $405.48 \pm 21.84$ & $391.37 \pm 18.02$ & $387.45 \pm 23.91 \boldsymbol{\Delta} \boldsymbol{\Delta}$ \\
\hline
\end{tabular}

Table 2. Effect of Bu-Shen-Jiang-Ya decoction on heart rate. ${ }^{*} P<0.05,{ }^{* *} P<0.01$, significantly different from the $C$ group. $\mathbf{\Delta} P<0.05, \mathbf{\Delta} \mathbf{\Delta} P<0.01$, significantly different from the Ca group.

maintenance of hypertension, because they may eventually lead to decompensation and ventricular extension, thus increasing the risk of heart failure and sudden death. Studies have confirmed that, with the development of $\mathrm{LVH}$, the incidence of cardiovascular events has increased by 6-10 times $^{9-12}$. Therefore, suppression of LVH was shown to improve cardiovascular outcome independently of other risk factors, and thus has been suggested as an intermediate endpoint ${ }^{13,14}$.

The mitogen-activated protein kinases (MAPKs) have been implicated as focal mediators of cardiac hypertrophy in both cell culture and genetically modified mouse models ${ }^{15}$. The extracellular signal-regulated kinase (ERK) signaling pathway, a branch of the greater MAPK signaling cascade, appears to induce a unique form of concentric cardiac hypertrophy ${ }^{16}$. It is activated in response to almost every stress- and agonist-induced hypertrophic stimulus examined to date, suggesting the straightforward hypothesis that these kinases are required for promoting the cardiac growth response ${ }^{17}$. Signaling through ERK cascade is classically initiated at the cell membrane by activation of the small $\mathrm{G}$ protein Ras that then recruits the MAP3K Raf- 1 to the plasma membrane, where it is activated ${ }^{18}$. More and more evidences showed that over expression of ERK signaling pathway plays an important role in cardiac hypertrophy ${ }^{19-21}$

Traditional Chinese medicine (TCM) has been reported to be effective for the treatment of hyperten$\operatorname{sion}^{22-24}$. However, there was little information available in literature about whether Chinese herbal medicine with anti-hypertensive effect could affect ERK pathway in LVH. Herbal compounds Bu-Shen-Jiang-Ya decoction (BSJYD) has been widely used in treating hypertension with kidney yin deficiency syndrome for many years. In our previous study, a prospective case series involving 108 hypertensive patients with kidney yin deficiency syndrome revealed a significant reduction of $13.1 \mathrm{mmHg}$ of systolic blood pressure (SBP) and $9.30 \mathrm{mmHg}$ of diastolic blood pressure (DBP) by BSJYD ${ }^{25}$. Additionally, no acute toxicology was identified on mice ${ }^{26}$. The significant BP-lowering effect of BSJYD has been confirmed in spontaneously hypertensive rats (SHRs); moreover, the possible cardioprotective mechanisms of BSJYD on hypertension may be related to up-regulating adiponectin and improving insulin resistance ${ }^{27}$. However, further study of its detailed anti-hypertensive and reversing ventricular hypertrophy mechanism is still needed. Here, we aimed to examine how ERK signal transduction induces LVH and whether BSJYD inhibits LVH bioactivities through the ERK signaling pathway effectively.

\section{Results}

Effect of BSJYD on SBP. After treatment for 8 weeks, SBP was significantly decreased in the Ca group, the $\mathrm{Bh}$ group, the $\mathrm{Bm}$ group, and the $\mathrm{Bl}$ group compared with the $\mathrm{C}$ group $(P<0.05)$. Compared with the Ca group, SBP was significantly increased in the $\mathrm{Bm}$ group, the $\mathrm{Bl}$ group, and the $\mathrm{C}$ group $(P<0.05)$, while no significant differences were identified between the Ca group and Bh group $(P>0.05)$ (as shown in Table 1).

Effect of BSJYD on HR. As shown in Table 2, HR were significantly lowered after 8 weeks in the Bh group $(P<0.01)$, while HR in the Bm group, the Bl group, and the Ca group were not significantly lowered when compared to the $\mathrm{C}$ group. As compared with the $\mathrm{Ca}$ group, the Bh group was significantly lowered $(P<0.05)$, while there is no significantly difference in the other groups $(P>0.05)$.

Effect of BSJYD on LVMI. After treatment for 8 weeks, LVMI in the WKY group, the Ca group, and the Bh group were significantly lowered when compared to the $\mathrm{C}$ group $(P<0.05)$. However, no significant difference between the Ca group and Bh group was identified (Fig. 1). 


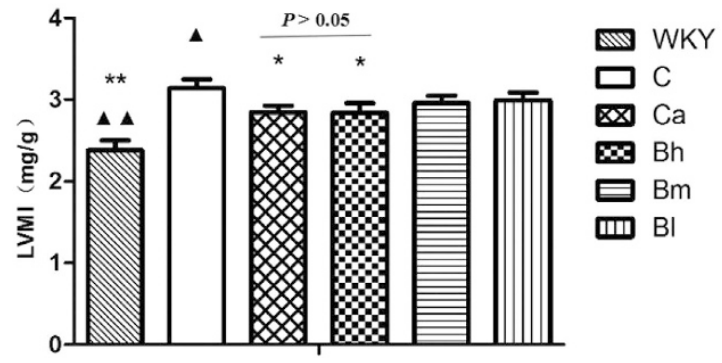

Figure 1. Effect of Bu-Shen-Jiang-Ya decoction on left ventricular mass index. ${ }^{*} P<0.05,{ }^{* *} P<0.01$, significantly different from the $\mathrm{C}$ group. $\boldsymbol{\Delta}_{P}<0.05, \mathbf{\Delta} \mathbf{\Delta} P<0.01$, significantly different from the Ca group.

Histological characteristics. Eight weeks after the treatment, the cardiac structure was measured through histological examinations. A significant difference was identified in the left ventricular apical biopsy between the $\mathrm{C}$ group and the Ca group (Fig. 2, HE staining 200x magnification). The single ventricular myocytes in the Bh group and the Ca group were larger than those in the $\mathrm{C}$ group.

Effect of BSJYD on the proteins expression of ERK signaling by WB analysis. Western blotting analysis was performed to examine the proteins expression of ERK signaling pathway, including BDNF, Ras, ERK1/2, and c-fox in left ventricular myocardium among the six groups $(n=12$ per group). Figure 3 (a) showed the expression of these proteins in the left ventricular areas. As shown in Fig. 3(b), the expression of BDNF was significantly increased in the $\mathrm{C}$ group, the $\mathrm{Ca}$ group, the $\mathrm{Bh}$ group, the $\mathrm{Bm}$ group, and the $\mathrm{Bl}$ group, when compared with that of the WKY group $(P<0.01)$. However, it was significantly decreased in the Bh group and the $\mathrm{Ca}$ group when compared with the $\mathrm{C}$ group $(P<0.01)$. However, no significant difference between the Ca group and Bh group on the expression of BDNF was identified $(P>0.05)$. As shown in Fig. 3(c), the expression of Ras was significantly increased in the $\mathrm{C}$ group, the $\mathrm{Ca}$ group, the Bh group, the Bm group, and the $\mathrm{Bl}$ group when compared with the WKY group $(P<0.01)$. However, when compared with that of the $\mathrm{C}$ group, the expression level of Ras was reduced in the Ca group, the Bh group, the Bm group, and the $\mathrm{Bl}$ group $(P<0.05)$. As compared to the Ca group, Ras was increased in the Bl group $(P<0.05)$; but no statistically significant differences were observed in the Bh group and the Bm group in terms of their expression of Ras $(P>0.05)$. As shown in Fig. 3(d), the expression of ERK1/2 was significantly reduced in the Ca group, the Bh group, the Bm group, the Bl group, and the WKY group when compared to the $\mathrm{C}$ group $(P<0.01)$. As compared to the Ca group, it was significantly increased in the $\mathrm{Bl}$ group $(P<0.05)$; however, no statistically significant difference was identified in the Bh group and the Bm group $(P>0.05)$. As shown in Fig. 3(e), c-fox was significantly increased in the $\mathrm{C}$ group, the Ca group, the Bh group, the Bm group, and the $\mathrm{Bl}$ group compared with the WKY group $(P<0.05)$. However, the expression of $\mathrm{c}$-fox was decreased in the Ca group, the Bh group, the Bm group, the Bl group, and the WKY group when compared with the $\mathrm{C}$ group $(P<0.05)$. It was increased in the Bh group $(P<0.05)$, significantly increased in the $\mathrm{Bm}$ group and the $\mathrm{Bl}$ group compared to the Ca group $(P<0.01)$.

Effect of BSJYD on the mRNA expression of ERK signaling by Real-time PCR assay. Real-time PCR was also performed to examine the mRNA expression of BDNF, Ras, ERK1/2, and c-fox in left ventricular myocardium. As shown in Fig. 4(a), the mRNA expression of BDNF in the $\mathrm{C}$ group, the Ca group, the Bh group, the $\mathrm{Bm}$ group, and the $\mathrm{Bl}$ group were significantly increased when compared to the WKY group $(P<0.01)$. As compared with the $\mathrm{C}$ group, the expression of BDNF mRNA in the Ca group, the Bh group, and the Bm group were significantly decreased $(P<0.01)$, while there is no difference in the $\mathrm{Bl}$ group $(P>0.05)$. As compared with the Ca group, the expression of BDNF mRNA in the Bh group, the Bm group, and the $\mathrm{Bl}$ group were significantly increased $(P<0.05)$. As shown in Fig. $4(\mathrm{~b})$, the mRNA expression of Ras in the $\mathrm{C}$ group, the Bh group, the Bm group, the $\mathrm{Bl}$ group, and the Ca group were significantly increased when compared to the WKY group $(P<0.05)$. As compared with the $\mathrm{C}$ group, the expression of Ras mRNA in the Ca group, the Bh group, and the Bm group were significantly decreased $(P<0.01)$, while there is no difference in the $\mathrm{Bl}$ group $(P>0.05)$. As compared with the Ca group, the expression of Ras mRNA in the Bl group was significantly increased $(P<0.01)$, while there were no difference in the Bh group and the Bm group $(P>0.05)$. As shown in Fig. 4(c), the mRNA expression of ERK1/2 in the $\mathrm{C}$ group, the $\mathrm{Bh}$ group, the $\mathrm{Bm}$ group, and the $\mathrm{Bl}$ group were significantly increased $(P<0.01)$; while there is no difference in the Ca group when compared to the WKY group $(P>0.05)$. The expression of ERK1/2 mRNA in the Ca group, the Bh group, and the Bm group were significantly decreased $(P<0.01)$, while there is no difference in the $\mathrm{Bl}$ group $(P>0.05)$ when compared to the $\mathrm{C}$ group. As compared to the Ca group, the expression of ERK1/2 mRNA in the Bl group was significantly increased $(P<0.01)$, while there were no difference in the Bh group and the Bm group $(P>0.05)$. As shown in Fig. 4(d), the mRNA expression of $c$-fox in the $C$ group, the $\mathrm{Ca}$ group, the $\mathrm{Bh}$ group, the $\mathrm{Bm}$ group, and the $\mathrm{Bl}$ group were significantly increased when compared to the WKY group $(P<0.01)$. The expression of $\mathrm{c}$-fox mRNA in the Ca group, the Bh group, the Bm group, and the $\mathrm{Bl}$ group were significantly decreased when compared with the $\mathrm{C}$ group $(P<0.01)$. As compared with the Ca group, c-fox mRNA in the Bh group, the Bm group, and the $\mathrm{Bl}$ group were significantly increased $(P<0.05)$. 


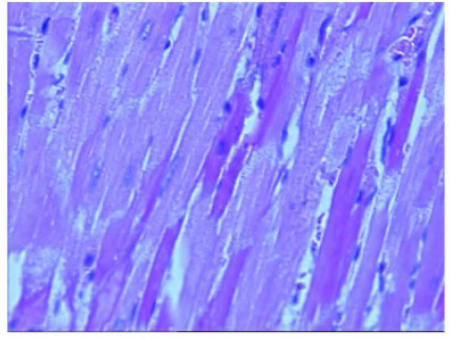

(a) WKY

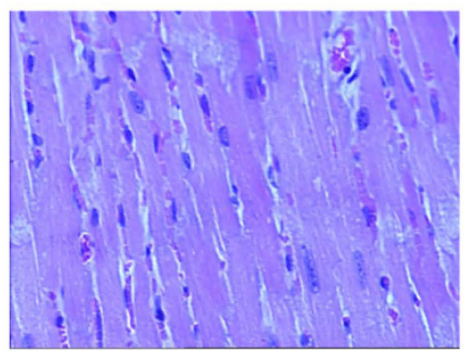

(d) $\mathrm{Bh}$

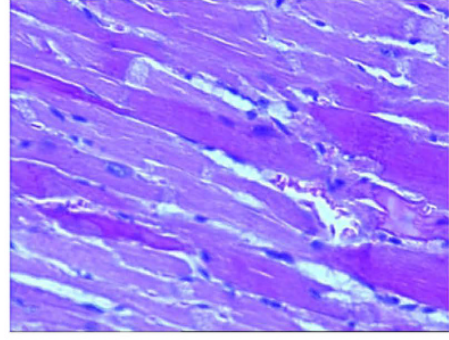

(b) $\mathrm{C}$

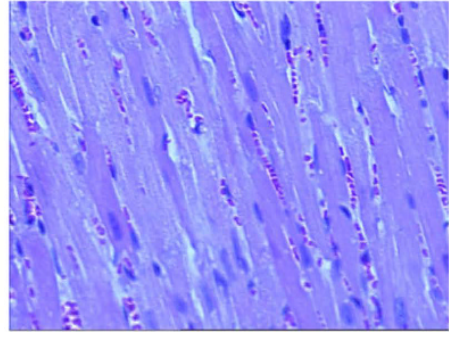

(e) $\mathrm{Bm}$

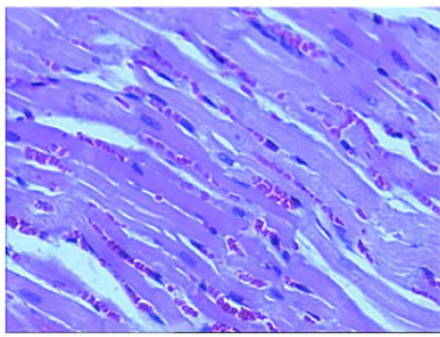

(c) $\mathrm{Ca}$

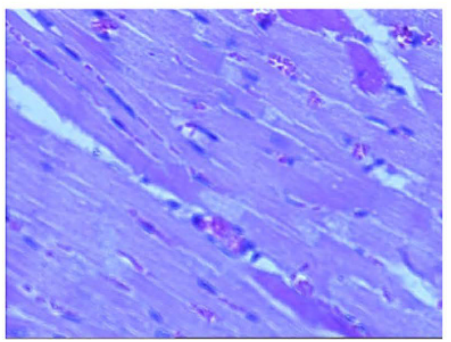

(f) $\mathrm{Bl}$

Figure 2. Microscopic observations $(200 \times)$ of myocardial tissue. After 8 weeks treatment of Bu-ShenJiang-Ya decoction, captopril, and distilled water administration, the left ventricular myocardium from 6 groups including (a) the WKY group, (b) the C group, (c) the Ca group, (d) the Bh group, (e) the Bm group, and (f) the $\mathrm{Bl}$ group was examined by haematoxylin and eosin.

\section{Discussion}

Hypertension could be classified into the categories of "vertigo" and "headache" in TCM theory ${ }^{28}$. Pattern or syndrome is the basic unit and key concept of $\mathrm{TCM}^{29}$. It has been identified that TCM patterns are associated with clinical manifestations of hypertension and its related target organ damage ${ }^{30}$. According to the diagnosis method of syndrome differentiation, kidney yin deficiency syndrome is the critical type of hypertension, which included dizziness, headache, tinnitus, dysuria, weakness, fatigue, sexual dysfunction, lassitude in loins and legs, red tongue with less fur, and deep thready pulse ${ }^{31,32}$. A literature analysis of 13, 272 hypertensive patients revealed that kidney yin deficiency syndrome account for about $26.27 \%$ and the proportion of kidney yin deficiency syndrome increased with age ${ }^{33,34}$. Therefore, Chinese herbal medicine nourishing kidney yin deficiency have been widely utilized by TCM physicians in the treatment of hypertension, especially in elderly patients ${ }^{35}$. Recent researches have demonstrated that traditional Chinese medicinal herbs and formulas with kidney yin-tonifying effect display good clinical antihypertensive efficacy and its underlying multiple cardiovascular protective mechanisms might be relevant to inhibiting the activity of sympathetic nerve, blocking the renin-angiotensin system, improving endothelial function, preventing target organ damage, inhibiting inflammation, and improving insulin resistance as well as glucose and lipid metabolism ${ }^{23,36,37}$. According to the TCM basic theory, BSJYD, which is originated from a famous TCM classic herbal formula Liu Wei Dihuang pill, belongs to the category of Chinese herbal medicine with nourishing kidney yin deficiency effects.

Antihypertensive therapy is the cornerstone of the treatment of hypertension ${ }^{38}$. Clinical trials have confirmed that antihypertensive therapy reduces the risk of cardiovascular disease outcomes, including incident stroke (by 35 to $40 \%$ ), myocardial infarction (by 15 to $25 \%$ ), and heart failure (by up to $64 \%)^{39-41}$. A recently published SPRINT study demonstrated that an intensive SBP control (less than $120 \mathrm{mmHg}$ ) might result in lower rates of fatal and nonfatal major cardiovascular events and death from any cause than standard SBP control (less than $140 \mathrm{mmHg})^{42}$. That is, strict BP control contributes to more cardiovascular protective effects. In our experiment, a significant reduction of SBP by BSJYD was identified when compared to the $\mathrm{C}$ group, and no significant difference between the Bh and $\mathrm{C}$ group was identified. Although difference between SHRs and hypertensive patients existed, the variation of BP in SHRs may partially reflect the antihypertensive effect of BSJYD. Biochemically, the pharmacological mechanism of BSJYD is closely related to the major active compounds including eucommia ulmoides lignans, gastrodin, polysaccharides of gastrodia rhizome, panax notoginseng saponins, and paeonol. Previously published studies also supported the BP-lowering effect of Chinese herbal medicine with nourishing kidney yin deficiency effects. A systematic review involving 6 randomized controlled trials with 527 people demonstrated that, compared with antihypertensive drugs alone, Chinese herbal formula with kidney-tonifying effects as adjunctive therapy significantly lowered SBP by $8.69 \mathrm{mmHg}$ in patients with senile hypertension ${ }^{43}$. Another systematic review including 6 randomized trials and a total of 555 hypertensive participants revealed a significant reduction of $9.31 \mathrm{mmHg}$ of SBP and $6.27 \mathrm{mmHg}$ of DBP by Liu Wei Dihuang pill as complementary therapy when compared to antihypertensive drugs alone ${ }^{44}$. Thus, this study provided evidence that BSJYD could be used to lower BP and is beneficial for hypertension treatment. 


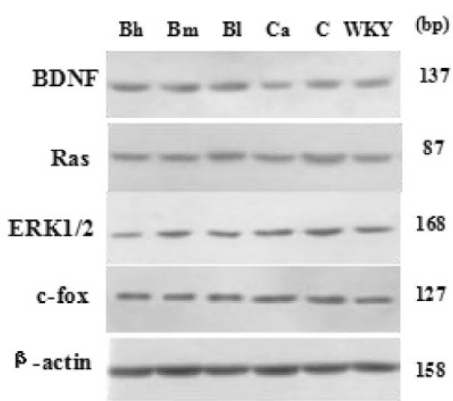

(a) left ventricular myocardium

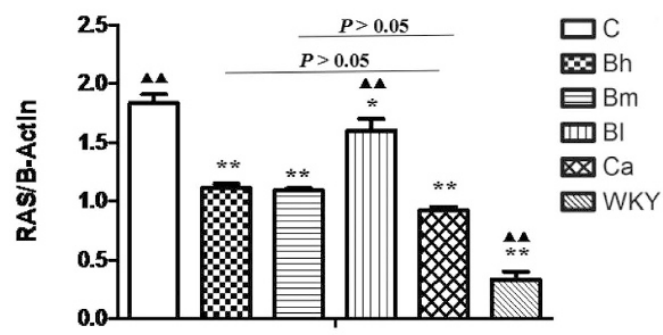

(c) Ras

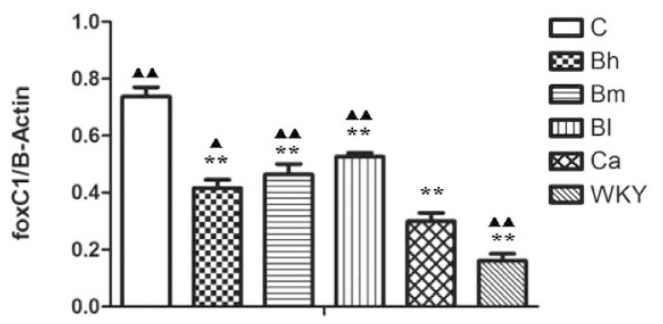

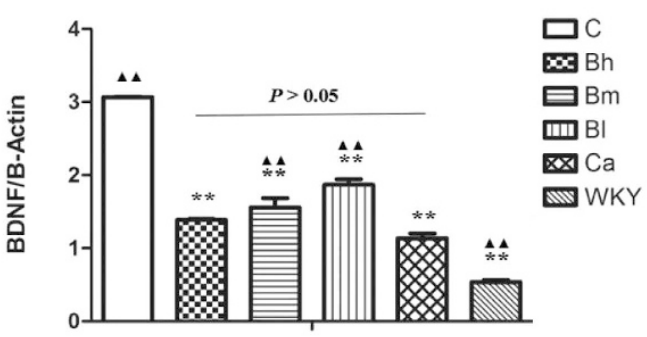

(b) BDNF

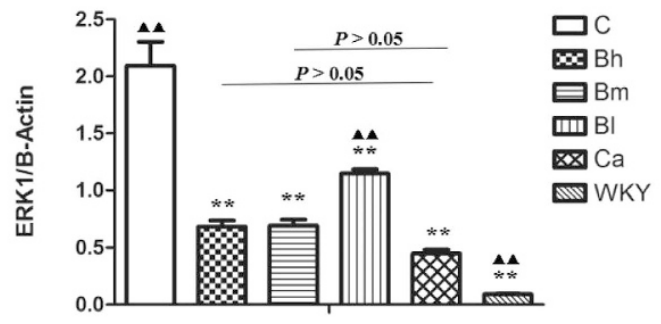

(d) ERK1/2

(e) c-fox

Figure 3. Effect of Bu-Shen-Jiang-Ya decoction on the proteins expression levels of ERK signaling in the left ventricular areas by western blotting analysis. (a) The expression levels of BDNF, Ras, ERK1/2, and c-fox in the left ventricular myocardium of the 6 groups. (b) The expression level of BDNF of the 6 groups in the left ventricular myocardium. (c) The expression level of Ras of the 6 groups in the left ventricular myocardium. (d) The expression level of ERK1/2 of the 6 groups in the left ventricular myocardium. (e) The expression level of $\mathrm{c}$-fox of the 6 groups in the left ventricular myocardium. Detailed information about the protein expression of ERK signaling was shown in the Supplementary Information file. ${ }^{*} P<0.05,{ }^{* *} P<0.01$, significantly different from the C group. $\boldsymbol{\Delta}_{P}<0.05, \mathbf{\Delta} \mathbf{\Delta} P<0.01$, significantly different from the Ca group.

Considerable evidence suggesting the important role of autonomic nervous system in BP regulation and development of hypertension have been established ${ }^{45-47}$. HR is regarded as an independent risk factor for hypertension $^{48}$. A clinic HR (more than $79 \mathrm{bpm}$ ) is a significant predictor of all-cause, cardiovascular, and noncardiovascular mortality in untreated older patients with isolated systolic hypertension ${ }^{49}$. The elevated resting HR should be paid more attention to in hypertensive patients ${ }^{50}$. In this experiment, HR in the Bh group was significantly decreased, suggesting that BSJYD is beneficial in inhibiting sympathetic nervous activity, thus lowering HR in SHRs. Biochemically, some active ingredients from the components of BSJYD, including hawthorn extract and paeonol, have a certain effect in reducing HR. Previous studies identified that oral administration of paeonol result in a reduction of $20.25 \mathrm{mmHg}$ in SBP and HR simultaneously ${ }^{51}$. Therefore, BSJYD not only exhibited certain antihypertensive effects, but also lowered HR significantly, which is similar to the pharmacological mechanism of $\beta$-blocker.

The results of our study showed a dose-dependently suppression of cardiac hypertrophy remodeling effect by BSJYD. It has been recognized that, in the chronic hypertension, elevated BP contributes to wall thickening and functional changes chronically in response to specific conditions, including LVH and cardiac fibrosis ${ }^{52}$. Increased LVM or LVH is a frequent complication of arterial hypertension, which is also an indicator of end-organ damage. The presence of $\mathrm{LVH}$ is associated with an increased rate of cardiovascular morbidity and mortality independent of other cardiovascular risk factors and, notably, independent of BP values ${ }^{53}$. Interestingly, both BP reduction and LVH suppression were accompanied by favorable outcome in the present research. It was identified that SHR 


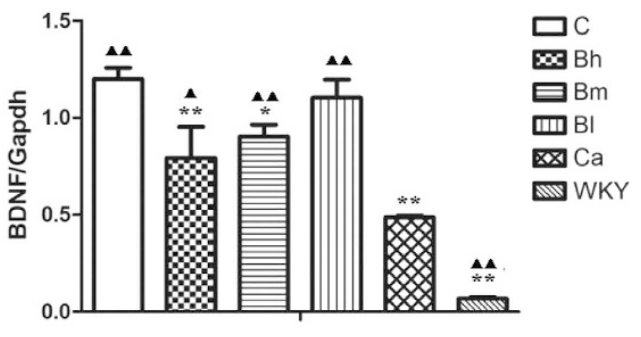

(a) BDNF

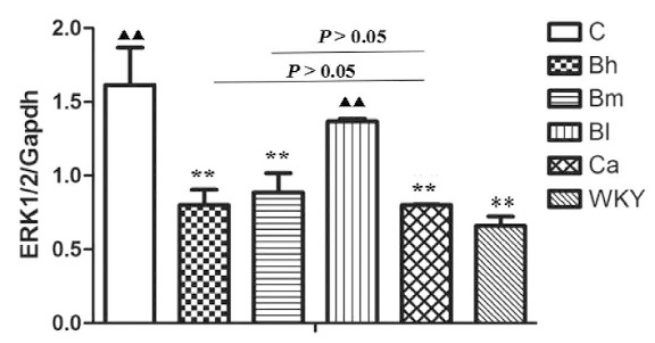

(c) ERK1/2

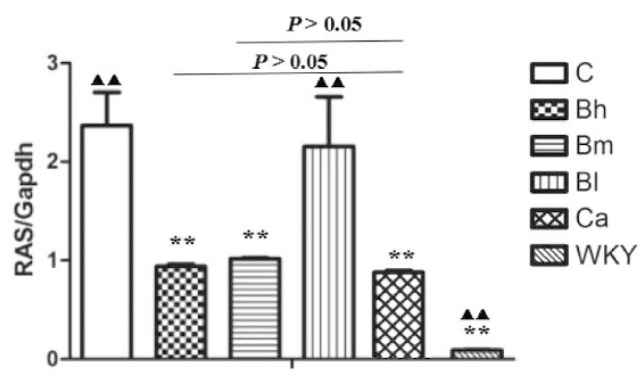

(b) Ras

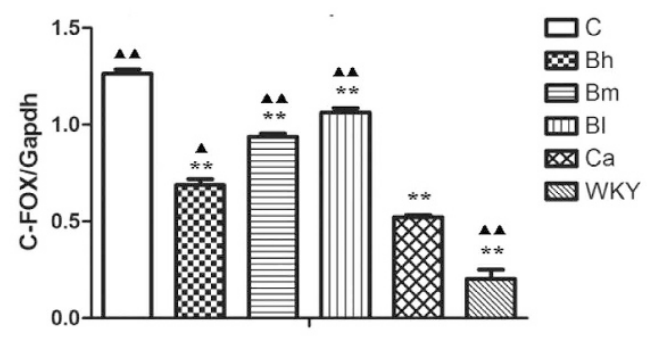

(d) c-fox

Figure 4. Effect of Bu-Shen-Jiang-Ya decoction on the mRNA expression levels of ERK signaling in the left ventricular areas by Real-time PCR assay. (a) The expression level of BDNF mRNA of the 6 groups in the left ventricular myocardium. (b) The expression level of Ras mRNA of the 6 groups in the left ventricular myocardium. (c) The expression level of ERK1/2 mRNA of the 6 groups in the left ventricular myocardium. (d) The expression level of c-fox mRNA of the 6 groups in the left ventricular myocardium. ${ }^{*} P<0.05,{ }^{* *} P<0.01$, significantly different from the C group. $\mathbf{\Delta}_{P<0.05,} \mathbf{\Delta} \mathbf{\Delta}_{P}<0.01$, significantly different from the Ca group.

continued to develop further high BP level, which could also be seen in other studies on SHR model, leading to a higher incidence of LVH when compared with WKY rats ${ }^{54,55}$. Obvious formation of cardiac hypertrophy and over expression of EKR signaling pathway were identified in the $C$ group. In our experimental study, after administration of BSJYD with 8 weeks, we were able to demonstrate marked reduction of LVMI, improvement in histological examination, and down regulation of EKR signaling pathway to some degree in the SHRs treated with BSJYD compared with untreated animals. It was suggested that the suppression effect of BSJYD on LVH may relate to the down-regulation of EKR signaling pathway.

In summary, the SHR treated with a daily dose of BSJYD over a period of 8 weeks demonstrated not only reduction in BP and HR with a dose-dependently manner, but also protection of target organ damage in hypertension. In this respect, our findings were consistent with previous reports about Chinese herbal medicines on SHR model ${ }^{56-60}$. We can draw the following conclusions from the present study: (a) BSJYD treatment could decrease BP and HR, and suppress LVH remodeling to a certain extent in SHR; (b) BSJYD treatment can inhibit the expression of BDNF, Ras, ERK1/2, and c-fox mRNA in LVH; and (c) a dose-dependent cardiovascular protective effects of BSJYD was identified.

\section{Conclusions}

Our present study suggested that BSJYD and captopril inhibit cardiac hypertrophy via a mechanism that may involve the regulation of the EKR signaling pathway. BSJYD treatment decreased BP and HR efficiently and reversed ventricular remodeling of SHRs. The mechanisms were possibly associated with the suppressive effect of BSJYD on the EKR signaling pathway. Therefore, our findings provided a theoretical basis for using BSJYD in the treatment of hypertension and its associated myocardial hypertrophy and fibrosis. BSJYD may be a new candidate cardioprotective drug for patients with hypertensive vascular diseases, which should be given priority for future preclinical and clinical studies.

\section{Materials and Methods}

Composition of BSJYD. BSJYD consists of 8 commonly used Chinese herbs as shown in Table 3 . The main chemical components of BSJYD were described in Fig. 5. All of these herbs with granule forms were provided and identified by Neo-Green Pharmaceutical Co., Ltd (Sichuan, China). The powdered BSJYD compounds, stored at $4^{\circ} \mathrm{C}$, were dissolved in distilled water prior to use.

Experimental animals. All animal experimental methods were carried out in accordance to the guidelines of China legislations on the ethical use and care of laboratory animals. The study protocol was approved by the Animal Review Board of the Guang'anmen Hospital, China Academy of Chinese Medical Sciences. Sixty 12-week-old male 


\begin{tabular}{|c|c|c|c|c|c|c|c|c|c|c|}
\hline English name & Latin name & $\begin{array}{l}\text { Chinese } \\
\text { name }\end{array}$ & $\begin{array}{c}\text { Place of } \\
\text { production } \\
\text { (Province) }\end{array}$ & $\begin{array}{l}\text { Collecting } \\
\text { time } \\
\text { (Season) }\end{array}$ & Part used & $\begin{array}{l}\text { Amount } \\
\text { used (g) }\end{array}$ & TCM efficacy & $\begin{array}{l}\text { Main chemical } \\
\text { components }\end{array}$ & $\begin{array}{l}\text { Pharmacological } \\
\text { activity }\end{array}$ & Ref \\
\hline Rehmannia & $\begin{array}{l}\text { Radix Rehmanniae } \\
\text { Glutinosae }\end{array}$ & Dihuang & Henan & Autumn & Root & 25 & $\begin{array}{l}\text { Nourishing } \\
\text { the liver and } \\
\text { kidney yin } \\
\text { and enriching } \\
\text { blood }\end{array}$ & \begin{tabular}{|} 
Rehmannia \\
glutinosa \\
polysaccharide, \\
rehmannia glutinosa \\
oligosaccharides, \\
and rehmannioside
\end{tabular} & $\begin{array}{l}\text { Lowering BP and } \\
\text { improving glucose } \\
\text { metabolism, lipid } \\
\text { metabolism, and } \\
\text { insulin resistance }\end{array}$ & $64-67$ \\
\hline Cornus Fruit & Corni Fructus & Shanzhuyu & Henan & Autumn & Fruit & 10 & \begin{tabular}{|l} 
Nourishing \\
the liver and \\
kidney yin, \\
inducing \\
astringency, \\
and preventing \\
prostration
\end{tabular} & $\begin{array}{l}\text { Iridoid glycoside, } \\
\text { aglycone, tannins, } \\
\text { polysaccharide, } \\
\text { organic acid, and } \\
\text { ester }\end{array}$ & $\begin{array}{l}\text { Lowering blood } \\
\text { glucose, improving } \\
\text { lipid metabolism } \\
\text { and insulin } \\
\text { resistance, and } \\
\text { protecting vascular } \\
\text { endothelial cells }\end{array}$ & $68-73$ \\
\hline Eucommia Bark & $\begin{array}{l}\text { Cortex Eucommiae } \\
\text { Ulmoidis }\end{array}$ & Duzhong & Sichuan & Summer & Bark & 10 & $\begin{array}{l}\text { Nourishing } \\
\text { the liver } \\
\text { and kidney, } \\
\text { strengthening } \\
\text { muscles and } \\
\text { bones, and } \\
\text { soothing the } \\
\text { fetus }\end{array}$ & $\begin{array}{l}\text { Eucommia ulmoides } \\
\text { lignans, Eucommia } \\
\text { ulmoides iridoids, } \\
\text { isoquercitrin, rutin, } \\
\text { eucomman A, } \\
\text { penylpropannoids, } \\
\text { and quercetin }\end{array}$ & $\begin{array}{c}\text { Lowering } \mathrm{BP}(\mathrm{NO} \uparrow \text {, } \\
\text { RAAS } \downarrow), \text { reversing } \\
\text { hypertensive } \\
\text { vascular } \\
\text { remodeling and } \\
\text { hypertensive } \\
\text { cardiac remodeling, } \\
\text { improving lipid } \\
\text { metabolism (HMG- } \\
\text { CoA reductase } \downarrow \text {, } \\
\text { Apo I } \uparrow), \text { lowering } \\
\text { blood glucose, and } \\
\text { improving insulin } \\
\text { resistance } \\
\end{array}$ & $74-79$ \\
\hline Gastrodia & Gastrodiae Rhizoma & Tianma & Sichuan & Spring & Tuber & 20 & $\begin{array}{l}\text { Calming the } \\
\text { liver, relieving } \\
\text { spasm, and } \\
\text { subduing wind }\end{array}$ & $\begin{array}{l}\text { Gastrodin and } \\
\text { polysaccharides of } \\
\text { gastrodia rhizome }\end{array}$ & $\begin{array}{c}\text { Lowering BP } \\
\text { (PPAR } \uparrow, \text { RAAS } \downarrow \text { ), } \\
\text { improving lipid } \\
\text { metabolism } \\
(\mathrm{AMPK} \uparrow \text { ) and } \\
\text { insulin resistance, } \\
\text { and impairing } \\
\text { vascular endothelial } \\
\text { function (ET-1 } \downarrow \text {, } \\
\text { eNOS } \uparrow)\end{array}$ & $80-82$ \\
\hline Notoginseng Root & Notoginseng Radix & Sanqi & Yunnan & Spring & Root & 3 & $\begin{array}{l}\text { Promoting } \\
\text { blood } \\
\text { circulation to } \\
\text { remove blood } \\
\text { stasis, stopping } \\
\text { bleeding, } \\
\text { dispersing } \\
\text { swelling, and } \\
\text { relieving pain }\end{array}$ & \begin{tabular}{|} 
Panax notoginseng \\
saponins \\
(Ginsenoside \\
Rb1, R1, and Rg1, \\
Notoginsenoside \\
R1, etc.)
\end{tabular} & $\begin{array}{c}\text { Lowering BP } \\
\text { (PI3K/Akt/eNOS } \\
\text { pathway } \uparrow \text { ), } \\
\text { protecting } \\
\text { the vascular } \\
\text { endothelium, } \\
\text { and improving } \\
\text { prethrombotic } \\
\text { state and lipid } \\
\text { metabolism }\end{array}$ & $83-85$ \\
\hline $\begin{array}{l}\text { Cortex of the Peony } \\
\text { Tree Rote }\end{array}$ & $\begin{array}{l}\text { Cortex Radicis } \\
\text { Moutan }\end{array}$ & Mudanpi & Anhui & Spring & Root bark & 10 & $\begin{array}{l}\text { Eliminating } \\
\text { pathogenic } \\
\text { heat, cooling } \\
\text { the blood, and } \\
\text { promoting } \\
\text { blood } \\
\text { circulation to } \\
\text { remove blood } \\
\text { stasis }\end{array}$ & Paeonol & $\begin{array}{c}\text { Lowering BP } \\
\text { and heart rate, } \\
\text { increasing the } \\
\text { arterial blood flow, } \\
\text { and improving } \\
\text { glucose metabolism } \\
(\mathrm{AMPK} \uparrow)\end{array}$ & $86-88$ \\
\hline Crataegus Fruit & Crataegi Fructus & Shanzha & Henan & Autumn & Fruit & 30 & \begin{tabular}{|} 
Promoting \\
digestion, \\
removing food \\
stagnation, \\
expelling tenia, \\
and promoting \\
blood \\
circulation to \\
remove blood \\
stasis \\
\end{tabular} & $\begin{array}{c}\text { Hyperoside, } \\
\text { apigenin, luteolin, } \\
\text { quercetin, } \\
\text { kaempferol, and } \\
\text { herbacetin }\end{array}$ & $\begin{array}{l}\text { Lowering BP } \\
\text { and heart rate, } \\
\text { improving lipid } \\
\text { metabolism,and } \\
\text { improving vascular } \\
\text { endothelial } \\
\text { dysfunction }\end{array}$ & $89-91$ \\
\hline Alisma & Rhizoma Alismatis & Zexie & Fujian & Winter & Rhizome & 30 & \begin{tabular}{|} 
Inducing \\
diuresis, \\
excreting \\
dampness, and \\
clearing heat
\end{tabular} & $\begin{array}{l}\text { Alisol A, alisol } \\
\text { B, and alisol A } \\
\text { 24-acetate }\end{array}$ & $\begin{array}{l}\text { Improving lipid } \\
\text { metabolism and } \\
\text { lowering blood } \\
\text { glucose (HMG- } \\
\text { CoA reductase } \downarrow \text {, } \\
\text { PPAR } \uparrow, \text { leptin } \downarrow \text { ) }\end{array}$ & 92,93 \\
\hline
\end{tabular}

Table 3. Composition of Bu-Shen-Jiang-Ya decoction. Abbreviations: $\uparrow$ : up-regulation; $\downarrow$ : down-regulation; AMPK: phosphorylated AMP activated protein kinase; Ang II: Angiotensin II; Apo: apolipoprotein; BP: blood pressure; eNOS: endothelial nitric oxide synthase; ET: endothelin; HMG-CoA: 3-hydroxy-3-methyl glutaryl coenzyme A; NO: nitric oxide; PPAR $\gamma$ : peroxisome proliferator-activated receptor $\gamma$; RAAS: renin-angiotensinaldosterone system; TCM: traditional Chinese medicine. 


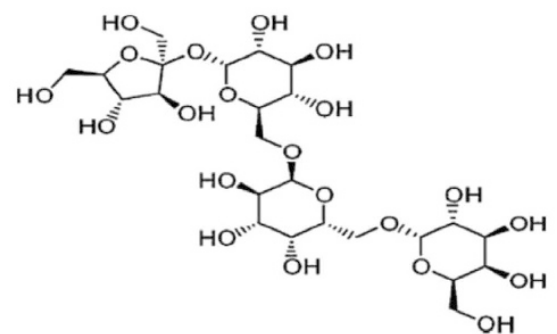

(a)

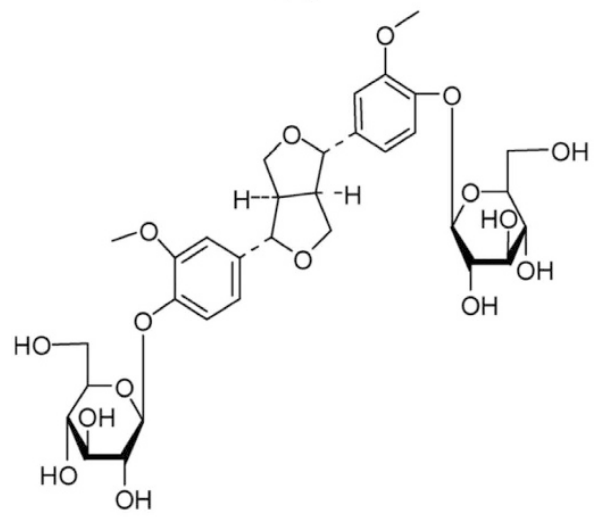

(c)

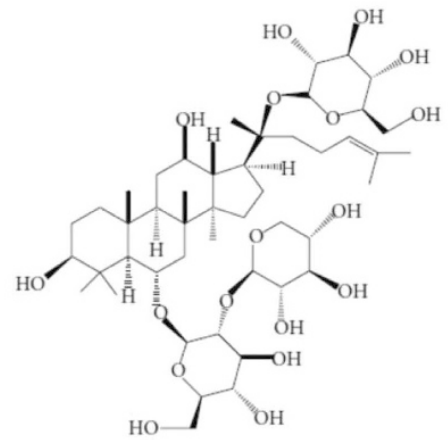

(e)<smiles>O=c1c(O[C@H]2O[C@H](CO)[C@@H](O)[C@H](O)[C@H]2O)c(-c2ccc(O)c(O)c2)oc2cc(O)cc(O)c12</smiles>

(g)<smiles>O=C(CO)C(O)C(O)C(O)C(O)C(=O)CO</smiles>

(b)<smiles>OCc1ccc(O[C@@H]2OC(CO)C(O)C(O)C2O)cc1</smiles>

(d)<smiles>COc1ccc(C(C)=O)c(O)c1</smiles>

(f)

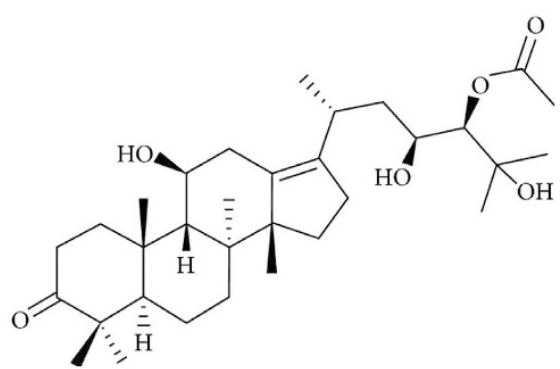

(h)

Figure 5. Chemical structure of the main active ingredients of Bu-Shen-Jiang-Ya decoction. (a) Stachyose of Rehmannia Glutinosa oligosaccharide. (b) 7-O-galloyl-D-sedoheptulose of Corni Fructus. (c) (+)-pinoresinoldi- $\beta$-d-glucopyranoside of Eucommia Bark. (d) Gastrodin of Gastrodia. (e) Ginsenoside R1 of Notoginseng Root. (f) Paeonol of Cortex of the Peony Tree Rote. (g) Hyperoside of Crataegus Fruit. (h) Alisol A of Alisma.

SHRs, weighing 240-280 g, and twelve 12-week-old male Wistar-Kyoto (WKY) rats, weighing 260-300 g, were purchased from Beijing Vital River Laboratory Animal Technology Co., Ltd. with certificate number: SCXK (Beijing) 2012-0001. Each cage contained one rat which had free access to laboratory chow and water and with the normal circadian rhythm. Ambient temperatures were between $18^{\circ} \mathrm{C}$ and $22^{\circ} \mathrm{C}$ with humidity $45-70 \%$. 
Administration of drugs. Sixty SHRs were trained for two weeks and then randomly allocated into five groups of twelve rats each. From the start of the third week, the rats were given drugs at 8:00 am every morning. The doses and routes are as follows: BSJYD high dose group $(6.75 \mathrm{~g} / \mathrm{ml}, \mathrm{Bh}), \mathrm{BSJYD}$ middle dose group $(3.375 \mathrm{~g} /$ $\mathrm{ml}, \mathrm{Bm}), \mathrm{BSJYD}$ low dose group $(1.6875 \mathrm{~g} / \mathrm{ml}, \mathrm{Bl}) ; 1$ group which received captopril $(0.125 \mathrm{~g} / \mathrm{ml}, \mathrm{Ca})$; and 1 control group of untreated SHRs (C). Additionally, a control group of $12 \mathrm{WKY}$ rats was established. Both control groups (C and WKY) were treated with distilled water. The drugs were administered for 8 weeks. All rats used in this study received humane care.

Measurement of SBP and heart rate (HR). SBP of all rats was measured using the indirect tailcuff plethysmographic method with a rat tail BP monitor (BP-100A, a noninvasive computerized tail-cuff system for measuring blood pressure in mice, Chengdu Technology \& Market Co., LTD, Sichuan, China). Rats were kept calm and conscious till pulsatory signals from the arteria caudilis were displayed steadily. At least 10 determinations were made on each rat and the mean of 6 readings within a $5-10 \mathrm{mmHg}$ range was taken as the $\mathrm{SBP}^{61}$. $\mathrm{HR}$ was recorded at the same time. BP and HR were measured every 2 weeks ( 4 times totally).

Measurement of left ventricular mass index (LVMI). After this period, all rats were sacrificed with urethane anesthesia. Their hearts were removed quickly and washed with cold normal saline, then dried with filter paper. Left ventricle was separated, and left ventricular mass (LVM) was accurately weighed by electronic balance. Then, left ventricular mass index (LVMI) was calculated by LVM/body weight ratios. Hearts of all animals were immediately stored in liquid nitrogen until western blot (WB) analysis and Real-time PCR (RT-PCR) were performed.

Histological examination. Left ventricular myocardium was cut into transverse sections and stained with haematoxylin and eosin $(\mathrm{H} \& \mathrm{E})^{62}$. The stained sections were examined under a light microscope (OLYMPUS BX51, Japan) and photographed at 200x magnification for morphological analysis.

Western blot analysis. The left ventricle of each rat was taken, kept at $-80^{\circ} \mathrm{C}$, and prepared for $\mathrm{WB}$ analysis. The following antibodies were used: BDNF (1: 500, Santa Cruz Biotechnology Inc.), Ras (1: 1000, Santa Cruz Biotechnology Inc.), ERK1/2 (1: 1000, Santa Cruz Biotechnology Inc.), and c-fox (1:1000, Cell Signaling Technology Inc.). Proteins were separated by $8 \%$ SDS-PAGE and transferred to PVDF membrane (Millipore, Temecula, CA, USA), which were then incubated with primary antibodies at $4{ }^{\circ} \mathrm{C}$. The membranes were further incubated with horseradish peroxidase-conjugated secondary antibodies (1:10000) for 1 hour at room temperature. ECL visualisation was performed, and the resulting images were captured using the Gene Gnome Gel Imaging System (Syngene Co.). Image J (NIH image, Bethesda, MD, USA) was used to analyze the gel images.

Real-time PCR. Left ventricle samples were frozen with the use of liquid nitrogen. Total RNA was extracted by use of TRIZol reagent (Invitrogen). Total RNA was quantified by spectrophotometry and reverse transcribed with use of the M-MLV Reverse Transcriptase System (Promega, Madison, WI) with oligo (dT) primers. mRNA expressions of BDNF, Ras, ERK1/2, and c-fox in left ventricle were examined by Real-time PCR with the use of LightCycler (Roche Applied Science, Indianapolis, IN) following the manufacturer's instructions. Primers used for PCR were as follows: $\beta$-actin: upstream, $5^{\prime}$-GACAAGATGGTGAAGGTCG-3', downstream, 5'-GTGGGTAGAGTCATACTGGAACAT-3', product: $158 \mathrm{bp}$; BDNF: upstream, 5'-CCTCCTCCCAT TTTGGTCCC-3', downstream, 5'-CACTGTTTTCCACGAGTGTCA-3', product: 137 bp; Ras: upstream, 5'-AAG GACCAGTTCCCAGAGGT-3' ${ }^{\prime}$, downstream, 5'-CCAACTCTACCTGCTTCCCG-3', product: 87 bp; ERK1/2: upstream, 5' -GGCATCCGAGACATCCTCAG-3', downstream, 5'-TATGTACTTGAGGCCCCGGA-3', product: $168 \mathrm{bp}$; and c-fox: upstream, 5'-GGGAGCTGACAGATACGCTC-3', downstream, 5'-GGTTCA GCCTTCAGCTCCAT-3', product: 127 bp. The mRNA sequences were obtained from GenBank (Bethesda, MD). Quantitative values were obtained from the threshold cycle value $(\mathrm{Ct})$, the point at which a significant increase in fluorescence was first detected. Experiments were performed in triplicate for each data point, and the data were analyzed with the $2^{-\triangle \triangle \mathrm{Ct}}$ method $^{63}$. The results of RT-PCR were confirmed by gel electrophoresis.

Statistical analysis. All experimental data were expressed as the mean $\pm \mathrm{SD}$. The data was statistically evaluated using one-way analysis of variance (ANOVA), and a post hoc analysis was performed using Fisher's least significant difference (LSD) test. The SPSS computer program (version 18.0) was used for data analyses. $p$ value less than 0.05 was considered to be statistically significant.

\section{References}

1. Sliwa, K., Stewart, S. \& Gersh, B. J. Hypertension: a global perspective. Circulation 123, 2892-2896 (2011).

2. Guo, F., He, D., Zhang, W. \& Walton, R. G. Trends in prevalence, awareness, management, and control of hypertension among United States adults, 1999 to 2010. J Am Coll Cardiol 60, 599-606 (2012).

3. Aronow, W. S. et al. ACCF/AHA 2011 expert consensus document on hypertension in the elderly. J Am Coll Cardiol 57, 1-78 (2011).

4. Kearney, P. M. et al. Global burden of hypertension: analysis of worldwide data. Lancet 365, 217-223 (2005).

5. McManus, R., Caulfield, M. \& Williams, B. NICE hypertension guideline 2011: evidence based evolution. BMJ 344, e181 (2012).

6. Ruilope, L. M. Current challenges in the clinical management of hypertension. Nat Rev Cardiol 9, 267-275 (2012).

7. Redfield, M. M. et al. Burden of systolic and diastolic ventricular dysfunction in the community: appreciating the scope of the heart failure epidemic. JAMA 289, 194-202 (2003).

8. Cuspidi, C., Sala, C., Negri, F., Mancia, G. \& Morganti, A. on behalf of the Italian Society of Hypertension. Prevalence of leftventricular hypertrophy in hypertension: an updated review of echocardiographic studies. J Hum Hypertens 26, 343-349 (2012).

9. Larstorp, A. C. K. et al. Changes in electrocardiographic left ventricular hypertrophy and risk of major cardiovascular events in isolated systolic hypertension: the LIFE study. J Hum Hypertens 25, 178-185 (2011). 
10. Gupta, S. et al. Left ventricular hypertrophy, aortic wall thickness, and lifetime predicted risk of cardiovascular disease: the dallas heart study. J Am Coll Cardiol Img 3, 605-613 (2010).

11. Bombelli, M. et al. Left ventricular hypertrophy increases cardiovascular risk independently of in-office and out-of-office blood pressure values. J Hypertens 27, 2458-2464 (2009).

12. Cowan, B. R. \& Young, A. A. Left ventricular hypertrophy and renin-angiotensin system blockade. Curr Hypertens Rep 11, 167-172 (2009).

13. Okin, P. M. et al. Regression of electrocardiographic left ventricular hypertrophy during antihypertensive treatment and the prediction of major cardiovascular events. JAMA 292, 2343-9 (2004).

14. Pierdomenico, S. D. \& Cuccurullo, F. Risk reduction after regression of echocardiographic left ventricular hypertrophy in hypertension: a meta-analysis. Am J Hypertens 23, 876-881 (2010).

15. Wang, Y. Mitogen-activated protein kinases in heart development and diseases. Circulation 116, 1413-1423 (2007).

16. Wilkins, B. J. et al. Calcineurin/NFAT coupling participates in pathological, but not physiological, cardiac hypertrophy. Circ Res 94, 110-118 (2004).

17. Kehat, I. \& Molkentin, J. D. Extracellular signal-regulated kinase 1/2 (ERK1/2) signaling in cardiac hypertrophy. Ann Ny Acad Sci 1188, 96-102 (2010).

18. Elrod, J. W. et al. Cyclophilin D controls mitochondrial pore-dependent $\mathrm{Ca}(2+)$ exchange, metabolic flexibility, and propensity for heart failure in mice. J Clin Invest 120, 3680-3687 (2010).

19. Kehat, I. et al. Extracellular signal-regulated kinases 1 and 2 regulate the balance between eccentric and concentric cardiac growth. Circ Res 108, 176-183 (2011).

20. Ferreira, A. J. et al. Angiotensin-converting enzyme 2 activation protects against hypertension-induced cardiac fibrosis involving extracellular signal-regulated kinases. Exp Physiol 96, 287-294 (2010).

21. Dominic C. H. et al. Opposing actions of extracellular signal-regulated kinase (ERK) and signal transducer and activator of Transcription 3 (STAT3) in regulating microtubule stabilization during cardiac hypertrophy. J Biol Chem 286, 1576-1587 (2011).

22. Xiong, X. J. Integrating traditional Chinese medicine into Western cardiovascular medicine: an evidence-based approach. Nat Rev Cardiol 12, e374 (2015).

23. Xiong, X. J. et al. Chinese herbal formulas for treating hypertension in traditional Chinese medicine: perspective of modern science. Hypertens Res 36, 570-579 (2013).

24. Xiong, X. J., Borrelli, F., Ferreira, A. S. Ashfaq, T. \& Feng, B. Herbal medicines for cardiovascular diseases. Evid Based Complement Alternat Med 2014, e809741 (2014).

25. Yang, X. C., Xiong, X. J. \& Wang, J. Clinical observation of 108 cases of primary hypertension treated with bu shen jiang ya therapy. World J Integr Tradit West Med 9, 1083-1086 (2014).

26. Liu, W., Wang, J., Xiong, X. J. \& Yang, X. C. Experimental study of bu shen jiang ya decoction on acute toxicology. Beijing J Tridit Chin Med 32, 647-649 (2013).

27. Yang, X. C., Xiong, X. J., Zhang, Y., Liu, Y. M. \& Wang, J. Impacts of bu shen jiang ya formula on adiponectin and insulin resistance in spontaneously hypertensive rats. World J Integr Tradit West Med 8, 1107-1110 (2013).

28. Wang, J. \& Xiong, X. J. Evidence-based Chinese medicine for hypertension. Evid Based Complement Alternat Med 2013, e978398 (2013).

29. Wang, J. Wang, P. Q. \& Xiong, X. J. Current situation and re-understanding of syndrome and formula syndrome in Chinese medicine. Int Med 2, e1000113 (2012)

30. Luiz, A. B., Cordovil, I., Filho, J. B. \& Ferreira, A. S. Zangfu zheng (patterns) are associated with clinical manifestations of zang shang (target-organ damage) in arterial hypertension. Chin Med 6, 23 (2011).

31. Xiong, X. J. et al. Trends in the treatment of hypertension from the perspective of traditional Chinese medicine. Evid Based Complement Alternat Med 2013, e275279 (2013).

32. Wang, J. \& Xiong, X. J. Current situation and perspectives of clinical study in integrative medicine in China. Evid Based Complement Alternat Med 2012, e268542 (2012).

33. Wang, J., Xiong, X. J. \& Liu, W. Traditional Chinese medicine syndromes for essential hypertension: a literature analysis of 13,272 patients. Evid Based Complement Alternat Med 2014, e418206 (2014)

34. Wang, J. \& Xiong, X. J. Control strategy on hypertension in Chinese medicine. Evid Based Complement Alternat Med 2012, e284847 (2012)

35. Wang, J. \& Xiong, X. J. Outcome measures of Chinese herbal medicine for hypertension: an overview of systematic reviews. Evid Based Complement Alternat Med 2012, e697237 (2012).

36. Yang, X. C., Xiong, X. J. \& Wang, J. Application of kidney-nourishing herbal medicine for treating hypertension. China J Chin Mater Med 38, 4015-4019 (2013).

37. Yang, X. C., Xiong, X. J. \& Wang, J. Application of kidney-nourishing herbal medicine for treating hypertension with insulin resistance. Chin J Integr Tradit Chin West Med 34, 637-640 (2014).

38. Angell, S. Y., Cock, K. M. D. \& Frieden, T. R. A public health approach to global management of hypertension. Lancet 385, 825-827 (2015).

39. Neal, B., MacMahon, S. \& Chapman, N. Effects of ACE inhibitors, calcium antagonists, and other blood-pressure-lowering drugs: results of prospectively designed overviews of randomised trials. Lancet 356, 1955-1964 (2000).

40. Chobanian, A. V. et al. And The National High Blood Pressure Education Program Coordinating Committee. The seventh report of the Joint National Committee on the Prevention, Detection, Evaluation and Treatment of High Blood Pressure. Hypertension 42, 1206-1252 (2003).

41. Psaty, B. M. et al. Health outcomes associated with anti-hypertensive therapies used as first-line agents: asystematic review and metaanalysis. JAMA 277, 739-745 (1997).

42. The SPRINT Research Group. A randomized trial of intensive versus standard blood-pressure control. N Engl J Med 373, 2103-2116 (2015).

43. Wang, J., Xiong, X. J. \& Yang, X. C. Is it a new approach for treating senile hypertension with kidney-tonifying Chinese herbal formula? a systematic review of randomized controlled trials. Evid Based Complement Alternat Med 2014, e473038 (2014).

44. Wang, J. et al. Chinese patent medicine liu wei di huang wan combined with antihypertensive drugs, a new integrative medicine therapy, for the treatment of essential hypertension: a systematic review of randomized controlled trials. Evid Based Complement Alternat Med 2012, e714805 (2012).

45. Julius, S. Autonomic nervous system dysregulation in human hypertension. Am J Cardiol 67, 3B-7B (1991).

46. Benetos, A., Rudnichi, A., Thomas, F., Safar, M. \& Guize, L. Influence of heart rate on mortality in a French population: role of age, gender, and blood pressure. Hypertension 33, 44-52 (1999).

47. Prasad, V. K. et al. Association of exercise heart rate response with incidence of hypertension in men. Mayo Clin Proc 89, 1101-1107 (2014).

48. Gillman, M. W., Kannel, W. B., Belanger, A. \& D'Agostino, R. B. Influence of heart rate on mortality among persons with hypertension: The Framingham Study. Am Heart J 125, 1148-1154 (1993).

49. Palatini, P. et al. For the Systolic Hypertension in Europe (Syst-Eur) Trial Investigators. Predictive value of clinic and ambulatory heart rate for mortality in elderly subjects with systolic hypertension. Arch Intern Med 162, 2313-2321 (2002). 
50. Ryu, M., Bayasgalan, G., Kimm, H., Nam, C. M. \& Ohrr, H. Association of resting heart rate and hypertension stages on all-cause and cardiovascular mortality among elderly Koreans: the Kangwha Cohort Study. J Geriatr Cardiol 13, 573-579 (2016).

51. Zhang, L. H., Xiao, P. G., Huang, Y. \& Qian, Y. K. Advances in pharmacology and clinical research of paeonol. Chin J Integr Trad West Med 16, 187-190 (1996).

52. Frohlich, E. D. et al. The heart in hypertension. N Engl J Med 327, 998-1008 (1992).

53. Brandt, M. C. et al. Renal sympathetic denervation reduces left ventricular hypertrophy and improves cardiac function in patients with resistant hypertension. J Am Coll Cardiol 59, 901-909 (2012).

54. Lieke, E. et al. Dietary fish oil improves endothelial function and lowers blood pressure via suppression of sphingolipid-mediated contractions in spontaneously hypertensive rats. J Hypertens 32, 1050-1058 (2014).

55. Sudesh, V., Carol, A. F., Sushil, P., Linda, L. \& Veeresh, G. Dietary $\alpha$-lipoic acid supplementation lowers blood pressure in spontaneously hypertensive rats. J Hypertens 18, 567-573 (2000).

56. Zhang, N. B., Huang, Z. G., Cui, W. D. \& Ding, B. P. Effects of puerarin on expression of cardiac Smad3 and Smad7 mRNA in spontaneously hypertensive rat. J Ethnopharmacol 138, 737- 740 (2011)

57. Kim, D. D., Sánchez, F. A., Durán, R. G., Kanetaka, T. \& Durán, W. N. Endothelial nitric oxide synthase is a molecular vascular target for the Chinese herb Danshen in hypertension. Am J Physiol Heart Circ Physiol 292, 2131-2137 (2007)

58. Wang, B. et al. Effect of traditional Chinese medicine Qin-Dan-Jiang-Ya-Tang on remodeled vascular phenotype and osteopontin in spontaneous hypertensive rats. J Ethnopharmacol 110, 176-182 (2007).

59. Shih, H. C., Lee, T. H., Chen, S. C., Li, C. Y. \& Shibuya, T. Anti-hypertension effects of traditional Chinese medicine Ju-ling-tang on renal hypertensive rats. Am J Chin Med 33, 913-921 (2005)

60. Ng, C. F. et al. The anti-hypertensive effect of Danshen (Salvia miltiorrhiza) and Gegen (Pueraria lobata) formula in rats and its underlying mechanisms of vasorelaxation. J Ethnopharmacol 137, 1366- 1372 (2011).

61. Duarte, J. et al. Antihypertensive effects of the flavonoid quercetin in spontaneously hypertensive rats. Brit J Pharmacol 133, 117-124 (2001).

62. Han, F. et al. Inhibition of dystrophin breakdown and endothelial nitric-oxide synthase uncoupling accounts for cytoprotection by 3-[2-[4-(3-chloro-2-methylphenyl)-1-piperazinyl]ethyl]-5,6-dimethoxy-1-(4-imidazolylmethyl)-1H-indazole dihydrochloride 3.5 hydrate (DY-9760e) in left ventricular hypertrophied mice. J Pharmacol Exp Ther 332, 421-428 (2010).

63. Livak, K. J. \& Schmittgen, T. D. Analysis of relative gene expression data using real-time quantitative PCR and the 2(-Delta Delta C (T)) Method. Methods 25, 402-408 (2001).

64. Chang, D. M., Yue, S. H., Liu, H. X., Yang, Y. T. \& Niu, G. P. Effect of Rehmannia on blood pressure in rats. J Xinxiang Med Coll 6, 9-11 (1989).

65. Cai, C. C., Wang, H. X. \& Wang, S. Effect of rehmannia glutinosa polysaccharide on the serum GLP-1 and GIP levels in obese diabetic rat model. Chin J Gerontol 33, 4506-4507 (2013).

66. Zhang, R. et al. Ameliorating effect and potential mechanism of rehmannia glutinosa oligosaccharides on the impared glucose metabolism in chronic stress rats fed with high-fat diet. Phytomedicine 21, 607-614 (2014).

67. Guo, X. N., Zhang, R. X., Jia, Z. P., Li, M. X. \& Wang, J. Effects of Rehmannia glutinosa oligosaccharides on proliferation of 3T3-L1 adipocytes and insulin resistance. China J Chin Mater Med 31, 403-407 (2006).

68. Han, J. C., Ji, H., Xue, C. F., Yin, M. \& Lou, F. C. Hypoglycemic effect of terpenes from fructus corni. Chin J Nat Med 4, 125-129 (2006).

69. Yamabe, N., Kang, K. S., Goto, E., Tanaka, T. \& Yokozawa, T. Beneficial effect of Corni Fructus, a constituent of Hachimi-jio-gan, on advanced glycation end-product-mediated renal injury in streptozotocin-treated diabetic rats. Biol Pharm Bull 30, 520-526 (2007).

70. Yokozawa, T. et al. Protective effects of morroniside isolated from Corni Fructus against renal damage in streptozotocin-induced diabetic rats. Biol Pharm Bull 31, 1422-1428 (2008).

71. Qi, M. Y., Liu, H. R., Dai, D. Z., Li, N. \& Dai, Y. Total triterpene acids, active ingredients from Fructus Corni, attenuate diabetic cardiomyopathy by normalizing ET pathway and expression of FKBP12.6 and SERCA2a in streptozotocin-rats. J Pharm Pharmacol 60, 1687-1694 (2008)

72. Liu, H., Xu, H. Q. \& Shi, Y. Protecting effect of total iridoid glycoside in Fructus Corni Officinalis on insulin resistance and blood lipid level of rats with type 2 diabetic cardiopathy. Pharmacol Clin Chin Mater Med 23, 36-39 (2007).

73. Hao, H. P., Xu, H. Q., Zhu, Q., Pi, W. X. \& Pan, Y. Effects of iridoside of corni fructus on NO, NOS, and ET in rats with diabetic vascular complications. J Nanjing Tradit Chin Med Univ 19, 157-158 (2003).

74. Luo, L. F. et al. Antihypertensive effect of Eucommia ulmoides Oliv. extracts in spontaneously hypertensive rats. J Ethnopharmacol 129, 238-243 (2010).

75. Gu, J. et al. Effects of lignans extracted from Eucommia ulmoides and aldose reductase inhibitor epalrestat on hypertensive vascular remodeling. J Ethnopharmacol 133, 6-13 (2011).

76. Li, Z. Y. et al. Hypertensive cardiac remodeling effects of lignan extracts from Eucommia ulmoides Oliv. bark-a famous traditional Chinese medicine. Am J Chin Med 41, 801-815 (2013).

77. Park, S. A. et al. Hypoglycemic and hypolipidemic action of Du-zhong (Eucommia ulmoides Oliver) leaves water extract in C57BL/ KsJ-db/db mice. J Ethnopharmacol 107, 412-417 (2006).

78. Lee, M. K. et al. Hypoglycemic effect of Du-zhong (Eucommia ulmoides Oliv.) leaves in streptozotocin-induced diabetic rats. Diabetes Res Clin Pract 67, 22-28 (2005).

79. Jin, X. et al. Ameliorative effect of Eucommia ulmoides Oliv. leaves extract (ELE) on insulin resistance and abnormal perivascular innervation in fructose-drinking rats. J Ethnopharmacol 128, 672-678 (2010).

80. Liu, W., Wang, L., Yu, J., Asare, P. F. \& Zhao, Y. Q. Gastrodin Reduces Blood Pressure by Intervening with RAAS and PPAR $\gamma$ in SHRs. Evid Based Complement Alternat Med 2015, e828427 (2015).

81. Kho, M. C. et al. Gastrodia elata Ameliorates High-Fructose Diet-Induced Lipid Metabolism and Endothelial Dysfunction. Evid Based Complement Alternat Med 2014, e101624 (2014).

82. Lee, O. H., Kim, K. I., Han, C. K., Kim, Y. C. \& Hong, H. D. Effects of acidic polysaccharides from gastrodia rhizome on systolic blood pressure and serum lipid concentrations in spontaneously hypertensive rats fed a high-fat diet. Int J Mol Sci 13, 698-709 (2012).

83. Pan, C. et al. Panax notoginseng and its components decreased hypertension via stimulation of endothelial-dependent vessel dilatation. Vascul Pharmacol 56, 150-158 (2012).

84. Liu, J. J. \& Chen, R. Effects of Panax notoginseng saponins on plasma vWF, t-PA and PAI-1 in paitents with hypertension. Med J Qilu 22, 221-222 (2007)

85. Chen, Y. B. \& Dong, Y. H. Clinical effect and pharmacological analysis of panax notoginseng saponins in the treatment of hyperlipidmia. China Med Pharm 6, 51-53, 139 (2006).

86. Zhang, J. Y., Zhao, L., Li, Y. K. \& Weng, W. L. Effect of paeonol on blood pressure and blood flow in artery of spontaneously hypertensive rats and its mechanisms related on vasomotion. China J Chin Mater Med 40, 4903-4907 (2015).

87. Ha, T. et al. Selected compounds derived from Moutan Cortex stimulated glucose uptake and glycogen synthesis via AMPK activation in human HepG2 cells. J Ethnopharmacol 131, 417-424 (2010).

88. Lau, C. H. et al. Pharmacological investigations of the anti-diabetic effect of Cortex Moutan and its active component paeonol. Phytomedicine 14, 778-784 (2007). 
89. Walker, A. F. et al. Hypotensive effects of hawthorn for patients with diabetes taking prescription drugs: a randomised controlled trial. Br J Gen Pract 56, 437-443 (2006).

90. Dalli, E. et al. Crataegus laevigata decreases neutrophil elastase and has hypolipidemic effect: a randomized, double-blind, placebocontrolled trial. Phytomedicine 18, 769-775 (2011).

91. Wang, J., Xiong, X. J. \& Feng, B. Effect of crataegus usage in cardiovascular disease prevention: an evidence-based approach. Evid Based Complement Alternat Med 2013, e149363 (2013).

92. Dan, H. et al. Hypolipidemic effects of Alismatis rhizome on lipid profile in mice fed high-fat diet. Saudi Med J 32, 701-707 (2011).

93. Li, Q. \& Qu, H. B. Study on the hypoglycemic activities and metabolism of alcohol extract of Alismatis Rhizoma. Fitoterapia 83, 1046-1053 (2012).

\section{Acknowledgements}

This work was supported by the National Natural Science Foundation Project of China (No. 81403375). The funders had no role in study design, data collection and analysis, decision to publish, or preparation of the manuscript.

\section{Author Contributions}

Xingjiang Xiong conceived the topic, completed the experimental study, and wrote the paper. Xiaochen Yang, Lian Duan, Wei Liu, Yun Zhang and Yongmei Liu completed the experimental study and helped to draft the manuscript together. Pengqian Wang, Shengjie Li and Xiaoke Li carried out the statistical analysis and drew the tables.

\section{Additional Information}

Competing financial interests: The authors declare no competing financial interests.

How to cite this article: Xiong, X. et al. Traditional Chinese medicine suppresses left ventricular hypertrophy by targeting extracellular signal-regulated kinases signaling pathway in spontaneously hypertensive rats. Sci. Rep. 7, 42965; doi: 10.1038/srep42965 (2017).

Publisher's note: Springer Nature remains neutral with regard to jurisdictional claims in published maps and institutional affiliations.

(c) (1) This work is licensed under a Creative Commons Attribution 4.0 International License. The images or other third party material in this article are included in the article's Creative Commons license, unless indicated otherwise in the credit line; if the material is not included under the Creative Commons license, users will need to obtain permission from the license holder to reproduce the material. To view a copy of this license, visit http://creativecommons.org/licenses/by/4.0/

(c) The Author(s) 2017 